\title{
Between Invention and Discovery: A. G. Bell's Photophone and Photoacoustic Research
}

\author{
Ja Hyon $\mathrm{Ku}$ \\ University College of Undeclared Majors, Youngsan University \\ (Received December 8, 2011; revised January 26, 2012; accepted February 1, 2012)
}

\begin{abstract}
The photophone, Alexander Graham Bell's device for transmitting sound through light was patented in 1880. It included the transmitter modulating and reflecting strong light like sunlight to a distant receiver which produced sound. In this working of the photophone, the discovery of the sound-emitting effect under illumination was very essential. Longing for being famous in the scientific community, Bell focused on presenting various methods for producing sounds and for maximizing the loudness by performing intensive research on the photoacoustic effect. Bell's scientific research on photoacoustics was successful in establishing himself as a scientist and laid a foundation of photoacoustic analysis. And his invention became a basis for other researchers' subsequent technologies like fiber-optic communication.
\end{abstract}

Key words: Sound, transmission, light, Bell, photophone, photoacoustic effect

ASK subject classification: General Area (0.1)

\section{Introduction}

The essential notion of sending sounds by light appeared in the late nineteenth century. Alexander Graham Bell (1847-1922), who had invented the telephone in 1875 , applied for a patent with the photophone in August, $1880^{[1]}$. This apparatus was the first wireless communication technology in that it enabled two persons to communicate each other without any electric wires to connect the two points like the telephone. Bell himself considered this apparatus as the most important invention during his life, but it was not commercialized like the telephone.

This research originated from the efforts to find the reasons of the failure of Bell's commercialization of photophone. This paper will first present the operating principle of the photophone and the cylindrical structure of the cell for collecting light in the receiver. Then it

\footnotetext{
*Corresponding author: Ja Hyon Ku (taramdge@hotmail.com) University College, Youngsan University, Junam-dong, Yangsan, Gyeongnam 626-790 Republic of Korea (Tel: +82-51-900-2185)
}

will present Bell's efforts to be a scientist in his research on the photoacoustic effect of emitting sounds by light. In the end, it will show that the invention was succeeded later to the modern technologies and Bell's scientific research was succeeded by a creation of new field of photoacoustic analysis.

\section{An Invention: Photophone}

Bell's first patent on the photophone was on the device for sending sound uploaded on light and extracting the sound signal from the modulated light by the action of specific materials sensitive to light. On April, 1, 1880, the first wireless call through the photophone was sent from the roof of the Franklin School to the window of Bell's laboratory, some 213 meters (700 ft) away. Bell transferred the photophone's rights to the American Bell Telephone Company in May $1880{ }^{[2]}$. The master patent for the photophone was issued in December $1880^{[3]}$. 
The operating principle of the photophone was similar to that of the telephone. Both of the technologies loaded sound signals by disturbing a property of the medium in order to send sounds to a distance. Bell's first telephone caused the variation of the resistance of the circuit by changing the length of the conducting wire by action of a vibrating diaphragm in the transmitter, making variable electric currents ${ }^{[4]}$. Bell's first photophone also caused the variation of the intensity of the light beam by vibrating the reflecting mirror in the transmitter by incident sound wave, making a modulated light beam.

The essential part of the way how to reproduce the signal transmitted by light is a light-sensitive material which is physically transformed by illumination. To reproduce sounds when the material was illuminated with modulated light, Bell suggested two different ways. One was to use materials which emitted sound directly, and the other was to connect to the circuit of the telephone a material which changed in conductivity under modulated illumination. The former method was based on his discovery of the photoacoustic effect of emitting sound by modulated light.

The forms of the transmitter and the receiver which Bell constructed first are well illustrated in the document of its patent. The transmitter (Figure 1) consists of a lens (a) collecting sunlight, an absorber ( $\left.a^{\prime}\right)$ of heat being carried by sunlight, a reflector (r) with a speaking

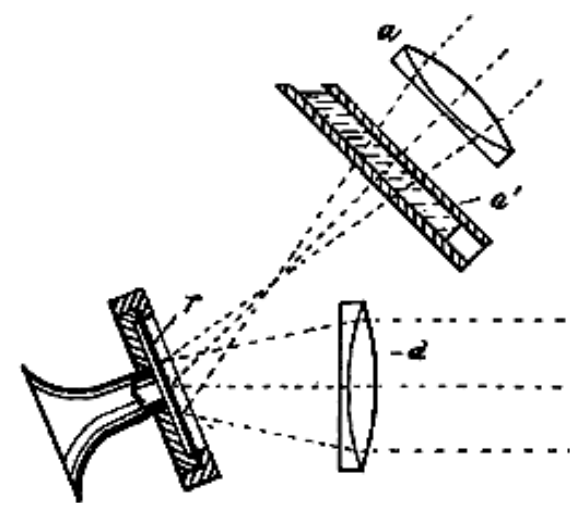

Fig. 1. The Transmitter of Bell's Photophone. Source: U. S. Patent No. 235,199 horn attached to the back surface, and a lens (d) collimating the reflected light from the reflector. The sound incident on the speaking horn disturbs the beam of sunlight which is being reflected from the reflector.

The receiver (Figure 2) consists of a parabolic mirror collecting the modulated sunlight from the transmitter, a selenium cell (a) at the focal point, which has the striped selenium around a cylinder of many disks of conductors and insulators, and the telephone circuit including the selenium stripes. Since the resistance of selenium increases under illumination, the disturbed sunlight causes the fluctuation of the resistance of selenium strips, which in turn leads to the oscillation of the intensity of the electric currents, producing a sound similar to the sound incident to the reflector of the transmitter.

In 1880, Bell presented for the receiver of the photophone two types of selenium cells, plate and cylinder. He obtained a separate patent for the cylindrical selenium cell for maximizing the control of electric currents by the modulated sunlight ${ }^{[4]}$. Photoconducting materials, like selenium, the conductivity of which changes under disturbed illumination, were pasted around the cylinder of the cell in the form of stripes so as to magnify the contact area between both poles since the amplitude of varying resistance of the photoconductor depends on its contact area. Thin disks of conducting material are insulated by many disks of insulator which have slightly smaller

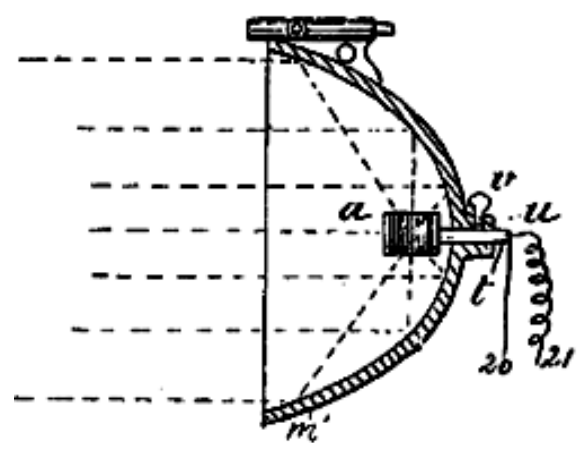

Fig. 2. The Receiver of Bell's Photophone. Source: U. S. Patent No. 235,497 
diameter than the conducting disks. The grooves around the disks of insulator are filled with photoconductors. (Figure 3) And all the disks are pierced with two conducting rods. One of the rods contacts with oddnumbered conducting disk but is insulated with the even-numbered conducting disks by insulating material and the other rod contacts with the even-numbered, but insulated with the odd numbered. (Figure 4) Thus, the odd numbered disks form an electric pole with very wide area, and the even numbered form the other pole of great area. And the photoconductors bridge the space between the two poles. In this structure, the photoconductors are located around the cylinder so that the photoconductor might receive the light from the parabolic mirror. In addition, a telephone circuit including a battery and a speaker is connected to the first and the last (even numbered) conducting disk of the cell. Then, when the surface of the cylinder receives modulated light coming from the transmitter, the variation of the conductivity of the photoconductors causes the variation of the electric current through the circuit.

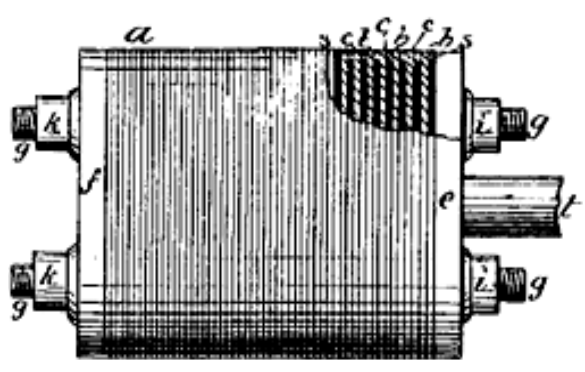

Fig. 3. Selenium Cell installed in the Photophone. Source: U. S. Patent No. 235,497

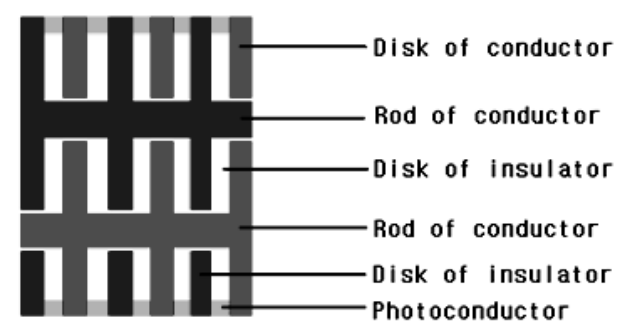

Fig. 4. Schematic Diagram of Cylindrical Selenium Cell.

\section{Bell's photoacoustical research}

Since Bell had special desire to be regarded as a scientist, he saw the photophone as a scientific discovery rather than a technical invention, and sought to proceed to the scientific community through the discovery ${ }^{[5]}$. His family background was pressing him to be a scientist rather than to remain a great inventor. His father Alexander Melville Bell (1819-1905) was a professor who was teaching diction and elocution in Scotland and London. He developed symbols for the fundamental speech sounds of all languages. And his son Alexander Graham helped his father in his lectures and started to investigate how to teach the dumb to speak. After Bell's family moved to Ontario, Canada in 1870, Bell started to teach the deaf in Boston. In 1872, he was offered a professorship at the newly created Boston University. While teaching at the university, he was supported by a Boston lawyer Gardiner Hubbard in his research on the multiple telegraph, which made a way to the invention of the telephone in $1876^{[6]}$. The invention of the telephone gave Bell unexpected fame and money. But he had great desire to be famous as a scientist. And his discovery of the emission of sounds under modulated light, the photoacoustic effect which could be applied to an essential part of the photophone, gave him good chance to enter into the scientific community and he took advantage of this unexpected opportunity.

As soon as Bell invented the photophone with his technical assistant Sumner Tainter, he applied for a patent with it and presented a paper on this before the American Association for the Advancement of Sciences. In this paper, Bell reported that when a thin plate made of various materials illuminated by a rapidly-interrupted beam of sunlight produced a sound. The pitch of the produced tone depended on the frequency of the interruption of sunlight and on the intensity of sunlight. 
As soon as Bell reported on the photophone, the scientific community took controversy about the cause of the photoacoustic effect. As Bell was active in the controversy, he sought to do various experiments concerning this phenomenon. In 1880, Bell went over to Paris to present papers to French scientists. During his stay in Paris, a new form of experiment occurred to Bell's mind, and he performed some preliminary experiments. He put some materials into a transparent tube and illuminated intermittent light to the materials so as to know which materials would produce a sound and how loud a sound they would produce. He found that a cigar made a loud sound and plain water did not. He ordered Tainter who was over the Atlantic in Washington D. C. to do similar experiments for screening various materials.

When he came back home in January, 1881, Bell saw the results produced by his assistant. Tainter gathered louder sounds from cotton, worsted, silk and other fibrous materials than from hard and rigid bodies like crystals and diaphragms. He also found that the darkest materials produced the loudest sound among various colors. To make cotton black, Tainter first pasted lampblack on cotton. And then, when he illuminated lampblack itself with intermittent light, he could hear the loudest sound from it ${ }^{[7]}$. Thus, Bell tried lampblack in the photophone to get satisfactory results. And then Bell found that a loose, porous, spongy, and black material is good for producing a sound under illumination. He explained why these materials are good for producing a sound; pores in this material are holding air, when the material is illuminated, the material expands due to the heat delivered by light causing to contract the air-space in the pores so as to expel the air. The heat delivered to the air causes the force of expansion to increase. When the light is cut off, the converse process takes place that a wave of rarefaction is originated from the contraction of the material ${ }^{[8]}$.

When the first report of Bell's discovery of the photoacoustic effect with disks made of photosensitive materials was presented in 1880, William H. Preece, the English technician, claimed, that the sound under the influence of intermittent light was caused by the expansion and contraction of the air in contact with the disk confined in the cavity behind the diaphragm ${ }^{[9]}$. But $3^{\text {rd }}$ Baron Rayleigh, the English acoustician, asserted from mathematical consideration of the heat flow that the sound could be caused by the bending of the plate under unequal heating ${ }^{[10]}$. Refuting Preece's opinion, Bell asserted that the expansion and contraction of materials by the flow of heat could emit sounds. He remarked that Preece's theory could not explain the effect in liquids and gases. Bell's subsequent investigations revealed that the liquids and gases are more effective than solids to emit a sound under intermittent illumination. Then Bell constructed careful settings to prove that lampblack would emit a sound to air directly, not from the vibration of the disk on which lampblack rested.

Bell's subsequent research led to the spectrophone, which opened the possibility of spectrum analysis by ears, especially through the effects of producing sounds by invisible light ${ }^{[11]}$. Bell removed the eye-piece of the spectroscope and put photoacoustic material in the focal point of the instrument behind a diaphragm containing a slit. When an intermittent light beam came into the modified spectroscope, so-called spectrophone, the absorption bands of the spectrum caused silence, the other bands a sound which was heard through a hearing tube connected to the spectrophone.

\section{Subsequent Researches}

Bell did not concentrate on commercializing the photophone but continued to see the photoacoustical effect as a topic for scientific research. Thus the further practical application of the apparatus went over other inventors. The radiophone, patented in 1900 by H. V. Hayes and E. R. Cram, was an 
apparatus transformed from Bell's photophone ${ }^{[12]}$. The transmitter of the radiophone emits a light beam disturbed by sound, and its receiver collects the light to reproduce the sound from it. Figure 5 shows a simple form of the radiophone. The generator $G$ produces electricity which makes radiate an arc lamp E installed at the focus of the parabolic mirror, and the microphone $\mathrm{M}$ which is connected in parallel to the arc lamp modulates the arc light by the voice incident to it. The disturbed light is reflected by the parabolic mirror so that it may be collimated, going to the parabolic mirror of the receiver. When the light arrives at the ash of cork or lampblack $L$ at the focus of the parabolic mirror of the receiver, the material emits a sound, which is transmitted to the earphones $\mathrm{B}$ through the tube $\mathrm{T}$.

Fundamental differences between this invention and Bell's photophone are that Hayes and Cram's radiophone uses the electric light source instead of sunlight and that the modulation of light is achieved, instead of by the vibration of the reflector, by the microphone connected in parallel to the circuit which includes the electric light source. Thus the radiophone could send modulated light in all weathers.

Fiber-optic communication, which is widely being used for sending voices nowadays, adopts the common principle of the photophone and the radiophone. Fiberoptic communication uses laser as a light source emitting modulated light through optical fibers, not through the free space ${ }^{[13]}$. In this sense, it guarantees more reliable speech quality and less possibility of eavesdropping. But since it is a means for communication through wire, fiber-optic communication is

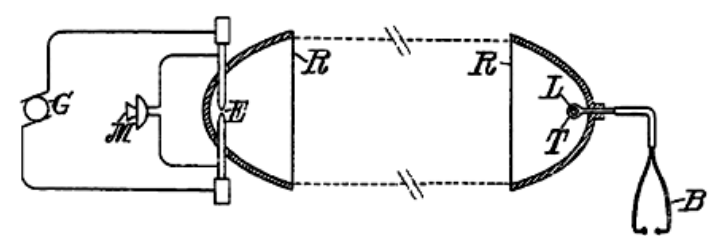

Fig. 5. Hayes and Cram's Radiophone. Source: U. S. Patent No. 154,630 possible only between stations connected by optical fibers. Subsequent researches for detecting dilute materials in samples by the spectrophone that Bell invented in the application of photoacoustics were successful in various fields, for example, the detection of the ozone depletion in the stratosphere in the 1970s.

\section{Conclusion}

Bell sought to reveal the nature and characteristic of the photoacoustic effect that is the basic principle of the photophone rather than to improve the apparatus for sending sound between a long distance. Through the intensive investigation of the phenomenon of emitting sounds under intermittent light, he found that various materials have this characteristic, and that black and loose materials like lampblack are very effective for sounding under intermittent illumination. He proceeded to the invention of the spectrophone, which was to be useful in gas analysis. Bell desired to be identified as a scientist through this scientific research and communication with the scientific community about his research on the photophone. Actually, Bell's photophone immediately attracted scientists' interest and made him famous in the scientific community. Many scientists were concerned with the cause of the phenomenon of the photoacoustic effect, debating each other with it.

The photophone was the first device for wireless communication, invented earlier than the radio communication realized by G. Marconi. The great success of its rival technology was one of the reasons why further development of the photophone was stagnated. Through the $20^{\text {th }}$ century, Bell's photophone was modified into a radiophone using artificial light sources, and then fiber-optic communication sending modulated light through optical fibers. And Bell's main focus of interest concerning this matter, the photoacoustic research based on his scientific discovery, also opened a new field of photoacoustic spectroscopy 
which contributed to the detection of dilute gases in the atmosphere in the late 20th century.

\section{Acknowledgment}

This thesis was supported by the research funding of Youngsan University.

\section{References}

1. A. G. Bell, "Apparatus for Signaling and Communicating, Called Photophone," U. S. Patent No. 235, 199, 1880.

2. R. V. Bruce, Bell: Alexander Graham Bell and the Conquest of Solitude, Cornell University Press, Ithaca, 1990.

3. L. Coe, The Telephone and Its Several Inventors: A History, McFarland, Jefferson, 1995.

4. A. G. Bell and S. Tainter, "Selenium Cell," U. S. Patent No. 235,497, 1880.

5. R. V. Bruce, Bell: Alexander Graham Bell and the Conquest of Solitude, Cornell University Press, Ithaca, 1990.

6. R. T. Beyer, Sounds of Our Times: Two Hundred Years of Acoustics, Springer, New York, 1999.

7. A. G. Bell, "Upon the Production of Sound by Radiant Energy," The National Academy of Sciences, pp. 2-4,
April 21, 1881.

8. A. G. Bell, Upon the Production of Sound by Radiant Energy, Gibson Brothers, Washington D. C. 1881.

9. W. H. Preece, "On the Conversion of Radiant Energy into Sonorous Vibrations," Proceedings of the Royal Society of London, pp. 513-514, 1881.

10. Rayleigh, "The Photophone," Nature 23, pp. 1-3, 1881.

11. A. G. Bell, Upon the Production of Sound by Radiant Energy, Gibson Brothers, Washington D. C. 1881.

12. H. V. Hayes and E. R. Cram, "Radiophony," U. S. Patent No. 654,630, 1900.

13. D. A. Kleinman et al., "Opto Acoustic Telephone Receiver,” U. S. Patent No. 4,002,897, 1977.

\section{Profile}

- Ja Hyon Ku

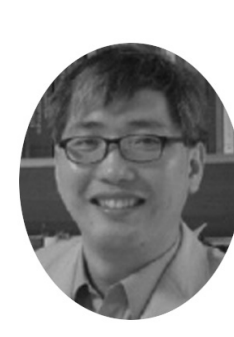

Ja Hyon Ku received a B.S. in physics, a M.S. and a Ph. D. in history of science from Seoul National University in 1989 , 1995, and 2002, respectively. From 1998 to 2003 , he was a part-time instructor at Seoul National University and other universities. From 2003, he has been a professor at Youngsan University, Korea. His main interest is the history of acoustics in the nineteenth century. 